\title{
PENGARUH PENYULUHAN MELALUI MEDIA VIDIO TERHADAP PENINGKATAN PENGETAHUAN TENTANG PEMERIKSAAN PAYUDARA SENDIRI (SADARI) PADA SISWI KELAS X DI SMAN 8 KENDARI
}

\author{
The Effect of Counseling Through Video Media On The Improvement of BSE Knowledge \\ In Class X Students at Senior High School 8 Kendari
}

\author{
Wa Ode Nova Noviyanti Rachman, Zuntari Dwi Putri \\ Program Studi Sarjana Kesehatan Masyarakat \\ Universitas Mandala Waluya \\ (waodenova.rachman@gmail.com, 0813892475733)
}

\begin{abstract}
ABSTRAK
Kanker payudara merupakan penyakit kanker dengan persentase kasus baru tertinggi di Dunia. Hal ini dipengaruhi oleh rendahnya pengetahuan remaja putri mengenai pemeriksaan SADARI . Upaya meningkatkan pengetahuan remaja putri salah satunya melalui penyuluhan SADARI. Tujuan penelitian ini adalah untuk mengetahui apakah ada pengaruh penyuluhan melaui media video terhadap peningkatan pengetahuan SADARI pada siswi kelas X di SMA Negeri 8 Kota Kendari. Desain penelitian ini adalah Quasi Experiment, dengan pendekatan One Group Pre-Test and Post-Test Design. Populasi dalam penelitian ini adalah semua siswi kelas X SMA Negeri 8 Kendari tahun 2020 yang berjumlah 93 orang.Sedangkan sampel penelitian berjumlah 48 responden. Tehnik pengambilan sampel menggunakan teknik Proportional Random Sampling. Analisis dilakukan dengan uji Wilcoxon. Hasil uji statistik Wilcoxon menunjukkan pengetahuan p-value $0,000(\mathrm{p}<0,05)$, dapat disimpulkan bahwa ada pengaruh penyuluhan kesehatan menggunakan video terhadap peningkatan pengetahuan SADARI pada siswi kelas X SMA Negeri 8 Kendari. Diharapkan pada pihak sekolah untuk mengadakan penyuluhan kesehatan dengan menggunakan video tentang SADARI yang bekerjasama dengan petugas kesehatan guna meningkatkan pengetahuan siswi.
\end{abstract}

Kata kunci: Remaja putri, pendidikan kesehatan, SADARI

\begin{abstract}
Breast cancer is a cancer with the highest percentage of new cases in the world. This is influenced by the low knowledge of young women about BSE examination. Therefore BSE examination needs to be understood and known by young women so that it can be applied regularly to detect breast health problems early. The objective of study was to determine whether there was an effect of counseling through video media on increasing BSE knowledge in class X students at Senior High School 8 Kendari. The study was a Quasi experiment design, with a on group pre-test and posttest. The population of this study was all students of class X Senior High School 8 Kendari in 2020 as much as 93 people who were divided into several classes while the research sample was 48 respondents. The sampling technique used proportional random sampling. The data were analyzed using the Wilcoxon test. The results of the Wilcoxon statistical test showed the p value was 0,000 knowledge $(p<0,05)$, it can be denied that there was an effect of health education using video on increasing BSE knowledge in class X Senior High School 8 Kendari. Therefore, it is expected that the school to provide health education by using videos about BSE in collaboration with health workers to increase students knowledge.
\end{abstract}

Keywords: Teenage girl, health education, BSE 


\section{PENDAHULUAN}

Kanker payudara yang juga disebut dengan Ca Mamae adalah salah satu jenis tumor ganas, yang terbentuk dari sel-sel payudara yang berkembang dan tumbuh secara tidak normal dan tidak terkendali, sehingga menyebar di jaringan atau organ di sekitar payudara atau dibagian tubuh lainnya. ${ }^{1}$ World Health Organization (WHO), menyebutkan insiden kanker payudara di dunia meningkat dari 12,7 juta kasus pada tahun 2008 menjadi 14,1 juta kasus tahun 2012, dengan jumlah kematian akibat kanker payudara meningkat dari 7,6 juta orang tahun 2008 menjadi 8,2 juta orang tahun 2012. Laporan GLOBOCAN (Global Cancer Observatory) Tahun 2012, terdapat 14 juta kasus baru kanker dan 8,2 juta kematian akibat kanker payudara di seluruh dunia dan meningkat menjadi 18,1 juta kasus baru di tahun 2018 dengan angka kematian sebesar 9,6 juta kematian. ${ }^{2}$

Prevalensi penyakit kanker payudara di Indonesia juga masih cukup tinggi. Data WHO (2018), menunjukkan bahwa kasus kanker yang paling banyak terjadi di Indonesia adalah kanker payudara, yakni sebesar $16,7 \%$ atau 58.256 kasus dari total 348.809 kasus. Data dari Kementerian Kesehatan juga menyatakan, bahwa angka kejadian kanker payudara di Indonesia di tahun 2018 mencapai 42,1 orang per 100 ribu penduduk. Rata-rata kematian akibat kanker ini mencapai 17 orang per 100 ribu penduduk.Artinya setiap 100.000 penduduk ada sekitar 42 orang menderita kanker payudara dan 17 orang diantaranya meninggal dunia. ${ }^{3}$
Di Provinsi Sulawesi Tenggara (Sultra), kanker payudara juga masih menjadi masalah kesehatan masyarakat khusunya pada kelompok wanita usia subur. Sekalipun tidak ada data yang dikeluarkan oleh Dinkes Provinsi Sultra, tetapi Rumah Sakit Umum Bahteramas yang merupakan rumah sakit rujukan di Provinsi Sulawesi Tenggara menunjukan data bahwa pasien rawat inap dan rawat jalan akibat kanker payudara untuk tahun 2015 sebanyak 36 pasien, tahun 2016 sebanyak 28 pasien, kemudian tahun 2017 mengalami peningkatan sebanyak 87 pasien dan pada tahun 2018 ditemukan sebanyak 90 pasien dengan 10 pasien diantaranya dinyatakan meninggal dunia. ${ }^{4}$

Dari data-data di atas menunjukan bahwa insiden penyakit kanker payudara masih cukup tinggi serta merupakan penyakit yang paling berbahaya jika menyerang wanita.Hal ini ini terjadi dikarenakan kurangnya kesadaran pada wanita untuk melakukan deteksi secara dini kanker payudara. Deteksi dini kanker payudara seharusnya harus dilakukan oleh setiap wanita yang sudah berumur 20 tahun ke atas, sehingga diharapkan kanker payudara bisa dapat diketahui secara dini dan bisa mendapatkan pengobatan dengan cepat sehingga peluang untuk sembuh menjadi lebih besar. Salah satu cara untuk melakukan deteksi dini kanker payudara adalah dengan melakukan pemeriksaan payudara sendiri atau biasa disebut dengan teknik SADARI. SADARI merupakan salah satu jenis pencegahan kanker payudara dengan mengecek sendiri kondisi payudara apakah 
terdapat benjolan ataupun perubahan lainnya pada payudara. ${ }^{5}$

Salah satu upaya yang dapat dilakukan guna memperkenalkan serta meningkatkan pengetahuan remaja putri mengenai SADARI adalah dengan memberikan penyuluhan kesehatan.Akan tetapi keberhasilan dari penyuluhan kesehatan tergantung juga kepada media yang digunakan saat penyuluhan. Media yang menarik akan meningkatkan motivasi audiens untuk belajar dan memahami materi penyuluhan. Salah satu jenis media penyuluhan yang menarik adalah media video. Media video ini merupakan salah satu dari media yang menyajikan informasi atau pesan secara audio dan kemampuan media video ini dianggap lebih menarik, sebab mengandung kedua unsur, yaitu di lihat dan didengar. ${ }^{6}$

Hasil observasi awal yang peneliti lakukan di SMAN 8 Kendari ditemukan bahwa, dari 10 siswi yang diwawancarai terdapat 7 siswi yang masih awam dengan yang namanya pemeriksaan payudara sendiri (SADARI). Berdasarkan permasalahan diatas maka penulis tertarik untuk mengadakan penelitian tentang Pengaruh Penyuluhan Melalui Media Vidio Terhadap Peningkatan Pengetahuan Tentang Pemeriksaan Payudara Sendiri (SADARI) Pada Siswi Kelas X di SMAN 8 Kendari.

\section{BAHAN DAN METODE}

Jenis penelitian yang digunakan adalah penelitian eksperimen dengan tujuan untuk mengetahui suatu pengaruh yang timbul sebagai akibat dari adanya perlakuan tertentu. Bentuk rancangan yang digunakan adalah One
Group Pretest-Postest yang mana pada desain ini terdapat pretest sebelum diberi perlakuan. Penelitian ini dilaksanakan pada bulan Juli tahun 2020. Populasi dalam penelitian ini adalah semua siswi kelas X SMA Negeri 8 Kendari tahun 2020 yang berjumlah 93 orang. Jumlah sampel dalam penelitian ini adalah 48 responden dengan penarikan sampel menggunakan Proportional Random Sampling. Uji statistik yang digunakan adalah uji Wilcoxon.

\section{HASIL}

Tabel 1 menunjukkan deskripsi karakteristik responden berdasarkan umur bahwa dari 48 responden terdapat 34 responden $(70,8 \%)$ berumur 15 tahun, dan 14 responden $(29,2 \%)$ berumur 16 tahun.

Tabel 1. Karakteristik Responden

\begin{tabular}{lcc}
\hline $\begin{array}{l}\text { Karakteristik } \\
\text { Responden }\end{array}$ & n (48) & \% \\
\hline Umur & & \\
15 tahun & 34 & 70,8 \\
16 tahun & 14 & 29,2 \\
\hline
\end{tabular}

Sumber: Data primer, 2020

Tabel 2 menunjukkan bahwa pengetahuan siswi sebelum diberikan penyuluhan dengan video tentang SADARI menunjukkan bahwa pada waktu dilaksanakan pretes dari 48 responden, sebanyak 29 responden $(60,4 \%)$ yang memiliki pengetahuan dengan kategori kurang tentang pemeriksaan payudara sendiri (SADARI) dan 19 responden $(39,6 \%)$ memiliki pengetahuan dengan kategori cukup. Sedangkan pengetahuan siswi sesudah diberikan penyuluhan dengan video tentang sadari menunjukkan bahwa sesudah diberikan 
penyuluhan dengan video, dari 48 siswi, sebanyak 3 responden $(6,2 \%)$ memiliki pengetahuan dengan kategori kurang tentang pemeriksaan payudara sendiri (SADARI) dan 45 responden $(93,8 \%)$ memiliki pengetahuan dengan kategori cukup.

Tabel 2. Analisis Univariat

\begin{tabular}{lcr}
\hline Variabel & n (48) & \% \\
\hline Sebelum & & \\
penyuluhan & & \\
Cukup & 19 & 39,6 \\
Kurang & 29 & 60,4 \\
\hline Sesudah & & \\
Penyuluhan & & \\
Cukup & 45 & 93,8 \\
Kurang & 3 & 6,2 \\
\hline Sumber: Data primer, 2020 &
\end{tabular}

Tabel 3 menunjukkan bahwa rata-rata pengetahuan responden tentang pemeriksaan payudara sendiri (SADARI) sebelum diberikan penyuluhan kesehatan dengan menggunakan videoadalah 50,27. Sesudah diberikan penyuluhan kesehatan menggunakan media audio didapatkan rata-rata pengetahuan responden tentang pemeriksaan payudara sendiri (SADARI) adalah 72,06. Perbedaan nilai rata-rata (mean) sebelum dan sesudah diberikan penyuluhan kesehatan menggunakan video adalah 21,79 maka dapat disimpulkan bahwa terdapat perbedaan rata-rata (mean) pengetahuan siswi tentang pemeriksaan payudara sendiri (SADARI) sebelum dan sesudah diberikan penyuluhan kesehatan dengan menggunakan media video pada kelompok eksperimen. Berdasarkan hasil uji statistik dengan uji Wilcoxon didapatkan nilai $p$-value $=0,000$. Karena $p$-value $<0,05$, maka Ho ditolak dan Ha diterima, yang berarti ada pengaruh penyuluhan kesehatan dengan video terhadap tingkat pengetahuan siswi tentang pemeriksaan payudara sendiri (SADARI) di SMA Negeri 8 Kendari Tahun 2020.

Tabel 3. Efektifitas Penyuluhan

\begin{tabular}{lccc}
\hline $\begin{array}{l}\text { Pengetahuan } \\
\text { responden }\end{array}$ & Mean & $\begin{array}{c}\text { Perbedaan } \\
\text { nilai mean }\end{array}$ & $\begin{array}{c}p \text { - } \\
\text { value }\end{array}$ \\
\hline $\begin{array}{l}\text { Sebelum } \\
\text { diberikan } \\
\text { penyuluhan }\end{array}$ & 50,27 & & \\
& & 21,79 & 0,000 \\
$\begin{array}{l}\text { Sesudah } \\
\text { diberikan } \\
\text { penyuluhan }\end{array}$ & 72,06 & & \\
\multicolumn{2}{l}{$\begin{array}{l}\text { Sumber: Data primer, 2020 } \\
\end{array}$} & & \\
\end{tabular}

\section{PEMBAHASAN}

Pengetahuan merupakan hasil dari tahu, dan ini terjadi setelah orang melakukan pengindraan terhadap suatu objek tertentu. ${ }^{7}$ Dari hasil penelitian sebelum diberikan penyuluhan kesehatan diketahui sebanyak 29 responden $(60,4 \%)$ memiliki pengetahuan kurang tentang pemeriksaan payudara sendiri (SADARI) dan 19 responden $(39,6 \%)$ dengan pengetahuan cukup. Hal ini diasumsikan bahwa sebagian besar responden masih bepengetahuan kurang tentang cara pemeriksaan payudara sendiri (SADARI). Kurangnya pengetahuan siswi ini disebabkan oleh beberapa faktor seperti faktor pengalaman.

Hasil wawancara dengan Kepala Sekolah di SMA Negeri 8 Kendari, ia mengatakan untuk kelas $\mathrm{X}$ belum pernah diadakan penyuluhan kesehatan khususnya tentang pemeriksaan payudara sendiri (SADARI). Hal ini yang membuat tingkat pengetahuan siswi Kelas $\mathrm{X}$ tentang pemeriksaan SADARI masih kurang baik. Hal ini dikuatkan dengan hasil observasi awal peneliti yang menemukan bahwa sebagian 
besar responden hanya mendapat informasi tentang SADARI hanya lewat buku-buku saja, belum ada petugas kesehatan yang datang memberikan penyuluhan di sekolah khususnya pada Kelas X.

Sebelum diberikan intervensi berupa penyuluhan kesehatan Siswi di SMA Negeri 8 masih memiliki pengetahuan yang kurang tentang SADARI. Hal ini terjadi karena para siswi masih kurang terpapar dengan sumber informasi tentang SADARI baik melalui video, televisi maupun penyuluhan kesehatan lain, sehingga menyebabkan siswi di SMA Negeri 8 Kendari tidak memiliki pengalaman untuk melakukan pemeriksaan SADARI. Kurangnya sumber informasi tentang kesehatan akan mempengaruhi pengetahuan seseorang, sebaliknya ketika seseorang memliliki sumber informasi yang memadai maka dapat meningkatkan pengetahuan seorang khususnya para siswi. Informasi bisa didapatkan dari media massa akan mempengaruhi fungsi kognitif dan afektif siswi. Sehingga tidak hanya pengetahuannya saja meningkat tetapi juga dapat membentuk sikap dan perilaku siswi tersebut.

Berdasarkan hasil penelitian tingkat pengetahuan siswi SMA Negeri 8 Kendari sesudah dilakukan intervensi berupa penyuluhan kesehatan dengan media video menunjukkan nilai peningkatan yaitu yang berpengetahuan kurang menurun menjadi 3 orang $(6,2 \%)$ dan yang berpengetahuan cukup naik menjadi 45 orang $(93,8 \%)$. Hasil ini dapat disimpulkan bahwa penyuluhan kesehatan dengan media video dapat meningatkan pengetahuan siswi SMA Negeri 8 Kendari.
Peningkatan pengetahuan siswi ini diasumsikan bahwa informasi yang disampaikan oleh peneliti tersampaikan dengan baik kepada responden atau siswi, sehingga terjadi peningkatan pengetahuan responden pada post-test. Pemilihan media video juga menjadikan materi yang disampaikan peneliti menjadi tidak monoton dan tidak membosankan sehingga terjadinya pemberian informasi menjadi lebih baik.

Sedangkan untuk 3 responden $(6,2 \%)$ yang masih memiliki pengetahuan yang kurang meskipun telah diberikan penyuluhan kesehatan, peneliti berasumsi bahwa ini disebabkan oleh beberapa faktor, seperti faktor peneliti, faktor responden, dan faktor sarana dan prasarana. Untuk faktor peneliti sendiri, peneliti berasumsi bahwa peneliti belum mampu mengontrol suasana dan proses penelitian secara maksimal. Sehingga terdapat beberapa responden yang kurang memperhatikan informasi yang disampaikan oleh peneliti, apalgi pada saat proses penelitian tidak dapat bertemu langsung dengan responden dikarenakan masih dalam situasi pandemik covid-19, sehingga proses penelitian dilakukan dengan menggunakan aplikasi zoom. Pada faktor responden terdapat beberapa alasan yang mungkin menyebabkan pengetahuan responden tetap, seperti kemampuan penyerapan informasi yang berbeda pada setiap orang serta intensitas perhatian responden atau kemauan responden untuk mendengarkan informasi yang diberikan oleh peneliti. Kurangnya intensitas perhatian responden mungkin disebabkan karena jaringan saat zoom tidak mendukung sehingga 
responden menjadi tidak fokus dalam mendengarkan materi penyuluhan, hal inilah yang menyebabkan tidak adanya perubahan pengetahuan responden walaupun telah mengikuti penyuluhan kesehatan. Sedangkan pada faktor sarana dan prasarana, yaitu terbatasnya penggunaan media bantu penyuluhan. Pada saat penelitian dilakukan alat bantu penyuluhan seperti kurang bagusnya proyektor yang digunakan saat penyuluhan sehingga tidak maksimal digunakan untuk menampilkan video secara lebih jelas dan luas.

Hasil uji bivariat menggunakan Uji Wilcoxon didapatkan nilai $p$-value $=0,000$ atau $p$-value $<0,05$ berarti Ha diterima dan Ho ditolak. Hal ini menunjukkan bahwa ada pengaruh pendidikan kesehatan dengan video tentang SADARI terhadap peningkatan pengetahuan siswi SMA Negeri 8 Kendari Tahun 2020. Ini menunjukkan penyampaian informasi tentang SADARI dengan penyuluhan kesehatan melalui media video dapat merubah tingkat pengetahuan siswi SMA Negeri 8 Kendari. Hal ini sejalan dengan penelitian yang dilakukan oleh Lestari (2019), yang menemukan hasil analisis data yaitu $p$ value $=0,000$ atau $p$-value lebih kecil dibandingkan $\alpha(0,05)$ yang artinya terdapat pengaruh pendidikan kesehatan dengan media audio visual (video) terhadap pengetahuan remaja putri tentang pemeriksaan payudara sendiri (SADARI) di SMAN 1 Kuta Utara. ${ }^{8}$

\section{KESIMPULAN DAN SARAN}

Dari hasil penelitian yang telah peneliti lakukan dapat disimpulkan adalah ada pengaruh penyuluhan kesehatan dengan video terhadap tingkat pengetahuan siswi tentang SADARI di SMA Negeri 8 Kendari. Kepada pihak sekolah, diharapkan agar ikut berperan dalam penyampaian informasi kesehatan kepada seluruh siswa/siswi guna meningkatkan pengetahuan siswa/siswi tentang kesehatan. Bagi siswi, sebaiknya pengetahuan yang sudah didapat, untuk diapilkasikan dalam kehidupan khususnya pada pemeriksaan payudara sendiri untuk dilakukan sebulan sekali. Kepada peneliti selanjutnya, diharapkan mampu meneliti faktor-faktor lain yang mempengaruhi pengetahuan remaja putri tentang pemeriksaan payudara sendiri (SADARI) contohnya pengalaman, kebudayaan, dan minat. Selain itu, diharapkan peneliti mampu melakukan pendidikan kesehatan dengan media ataupun metode yang berbeda.

\section{DAFTAR PUSTAKA}

1. Kemenkes RI. Situasi penyakit kanker. Jakarta; 2015.

2. GLOBOCAN. Estimated Cancer Incidence, Mortality And Prevalence Worldwide In 2018. International Agency for Research on Cancer (IARC); 2018.

3. Kementrian Kesehatan RI. Panduan Penatalaksanaan Kanker Payudara. Komite Penanggulangan Kanker Nasional. Jakarta; 2013.

4. Rumah Sakit Umum Bahteramas. Laporan Tahunan Rumah Sakit Umum Bahteramas. Kendari; 2019.

5. Irianto, K. Seksologi Remaja. Bandung: Alfabeta. 2014. 
6. Kementrian Kesehatan RI. Infodatin: Stop

Kanker. Jakarta: Pusat Data dan Informasi

Jakarta; 2015.

7. Notoatmodjo, Soekidjo. Promosi

Kesehatan dan Prilaku Kesehatan. Jakarta:

Rineka Cipta. 2014.

8. Lestari RTR, Laksmi IGAS, Sintari SNN.

Pengaruh Pendidikan Kesehatan dengan

Media Audio Visual Terhadap

Pengetahuan Remaja Putri Tentang

Pemeriksaan Payudara Sendiri (SADARI).

Bali Medika Jurnal. 2019;6(1):50-57. 